\title{
Availability and Dispensing Practices for Antimalarials and Antimicrobials in Western Kenyan Pharmacies
}

\section{Francis Wafula*}

Kenya Medical Research Institute/Welcome Trust Research Programme, Nairobi, Kenya

\begin{abstract}
Background: Specialized drug shops (SDSs) provide quick and convenient access to medicines in developing countries such as Kenya and are often the first point of call for common illnesses. Policymakers are increasingly looking for ways of including them in the provision of health services. However, concerns still linger over the quality of
\end{abstract} services SDSs offer.

Objectives: This study set out to describe the availability of antimalarials and antibiotics in rural and urban SDSs, and explore the factors that influence the dispensing practices of attendants.

Methods: The study was conducted in SDSs in 2 Kenyan districts: Bungoma South and Kakamega Central. The study had 3 data collection activities: a census to generate a list of SDSs; a provider survey to describe the availability of antimalarials and antibiotics, and characteristics of dispensers; and a mystery shopper survey to describe the dispensing practices of SDS attendants.

Results: Data were collected from 213 SDSs. The availability of most antimalarials and antibiotics was high, with TB medicines and artemisinin monotherapy treatments being the least available. Nearly all SDSs dispensed partial doses of amoxicillin without prescription, with only one quarter asking about additional symptoms, or advising against partial doses. Rural SDSs had a higher likelihood of dispensing without prescription $(p<0.001)$, with urban pharmacies being more likely to ask about additional symptoms or advise against partial doses ( $p<0.001$ for both). Attendants were less likely to sell ACT treatments without prescription, compared to amoxicillin, although they were also less likely to advise against buying incomplete doses. Over half of SDSs sold an ACT that had been obtained illegally from the public sector. Multivariate analysis showed recent regulatory inspection and presence of staff with pharmacy qualification to have no association with quality of dispensing practices.

Conclusions: The study highlighted the problem of inappropriate medicine use within communities. Indiscriminate dispensing habituates poor medicine use practices, which can result in the development and spread of resistance. Policy should focus on strengthening regulatory enforcement, in combination with education for dispensers, and promotion of public awareness. More research is required to describe in-depth, reasons underlying the dispensing practices observed, and how they can be improved to strengthen the role of retailers in provision of antimalarials and antibiotics within rural communities.

Keywords: Antibiotics; Antimalarials; Pharmaceutical services; Drug shops; Kenya

\section{Introduction}

Malaria and bacterial infections remain a major cause of mortality in Sub-Saharan Africa [1]. It is estimated that over 3.4 million deaths resulted from lower respiratory tract infections in 2008, with malaria accounting for over 820,000 deaths [2]. The majority of these deaths occur in children under 5 , despite there being effective treatments for the most common infections [3].

Effective management of infections requires early detection and initiation of treatment with effective medicines [4]. However, access to early treatment remains a major problem in many parts of SubSaharan Africa. Barriers include long distances to the nearest treatment point, poor road network and terrain, and lack of money to pay for transportation [5]. The access problem is compounded by frequent medicine stock-outs at health facilities [6].

For these reasons, large proportions of the population seek treatment from private medicine retailers, whose community penetration is generally greater that health facilities. Aside from having better geographic accessibility, retailers provide quicker treatment, and will usually have longer and flexible operating times [7]. Additionally, they may have a lesser problem with stock-outs, and offer credit facilities and flexible payment terms in certain places $[8,9]$.

In Sub-Saharan Africa, private medicine retailers include shops that specialize in medicines, and those that sell selected medicines alongside groceries and other household items [10]. We use the term specialized drug shops (SDSs) to refer to the former; the latter category is commonly referred to as general shops [11].

The specialized drug shops category will typically include retail pharmacies and registered and unregistered drug shops [9]. Pharmacies require a pharmacist to operate, and will usually be allowed to sell all types of medicines. Due to small numbers of pharmacists, some countries allow non-pharmaceutical staff to operate SDSs. These shops are commonly referred to as drug shops, and will usually have permission to sell a limited range of medicines, particularly in rural areas.

Despite their popularity, questions have been raised over the quality of services provided by SDSs. Studies show rampant dispensing of

*Corresponding author: Francis Wafula, Kenya Medical Research Institute/ Wellcome Trust Research Programme, Nairobi, Kenya, Tel: +254-20 2710672/2715160; Fax: +254-20 2711673; E-mail: info@kilifi.kemri-wellcome.org

Received December 23, 2012; Accepted January 21 2013; Published January 25, 2013

Citation: Wafula F (2013) Availability and Dispensing Practices for Antimalarials and Antimicrobials in Western Kenyan Pharmacies. Pharmaceut Reg Affairs 2 106. doi:10.4172/2167-7689.1000106

Copyright: (c) 2013 Wafula F. This is an open-access article distributed under the terms of the Creative Commons Attribution License, which permits unrestricted use, distribution, and reproduction in any medium, provided the original author and source are credited. 
antimalarials and antibiotics without prescription, with the medicines being given in cases where they are not required. In Ghana, threequarters of patients who purchased an antimalarial prior to visiting a health facility used it inappropriately, whereas in Nigeria, nearly all retailers sold an antibiotic for diarrhoea, despite most knowing that rehydration therapy was the recommended treatment $[12,13]$. Such indiscriminate dispensing may lead to drug wastage and contribute to resistance [14].

Like the rest of Sub-Saharan Africa, SDSs are an important component of the Kenya health system. Previous studies have shown that between $26-69 \%$ of the Kenyan population visit retailers as the first point of contact for common illnesses such as fever [15-18]. In Kenya, only pharmacies are recognized by law. However, unlicensed outlets operating under unqualified personnel are common [19]. For this reason, we use the broader term 'SDS' to include both pharmacies and unlicensed shops selling medicines.

Specialized drug shops in Kenya are known to comply poorly with regulations. Studies have shown that most shops lack the required personnel, equipment and materials, and do not comply with structural regulatory requirements for a pharmacy [20]. As a result, the large numbers of individuals who seek care from the SDSs may not receive policy-recommended treatments.

The Kenyan malaria treatment policy allows SDSs to stock antimalarials. However, only selected first-line medicines for uncomplicated malaria may be sold without prescription [21]. The current first-line treatments for malaria are the artemisinin-based combination therapies (ACTs). Unlike antimalarials, dispensing of antibiotics without prescription is not allowed, regardless of the nature of the infection or category of antibiotic in question. In addition to this requirement, the government discourages retail provision of tuberculosis (TB) medicines, for fear of spreading resistance (Personal Communication, manager at the Division of Tuberculosis). Despite the clear requirements, poor compliance to antibiotic policies has been cited as major cause of antimicrobial resistance in the country [22].

While inappropriate dispensing practices have been documented in Sub-Saharan Africa [23,24], less effort has gone towards understanding predictors for such practices. Low availability of qualified personnel is often given as the reason behind poor dispensing practices, and can be expected to play a major role in a country like Kenya, where unlicensed pharmacies are purported to outnumber the licensed ones [19]. Other factors that blamed for poor dispensing include inadequate knowledge and low rates of regulatory inspection. This study set out to assess the availability and dispensing practices for selected antimalarials and antibiotics across SDSs in 2 rural Kenyan districts.

\section{Methodology}

The study population was SDSs in 2 districts from the Western region: Bungoma South and Kakamega Central. Both districts have a high population density (602 for Bungoma and $723 \mathrm{~km}^{2}$ for Kakamega, against a national average of 68 per $\mathrm{km}^{2}$ ). The commonest causes of morbidity and mortality in the region are malaria, diarrhoea, respiratory diseases, and HIV/AIDS [25,26]. The 2 districts have high poverty levels, with 51 and $54 \%$ of individuals living below the poverty line in Bungoma and Kakamega respectively [27]. The majority of the population reside in rural locations, although both districts have a major town.

Health facilities in the 2 districts suffer from low staffing levels, with the doctor-patient ratios of 1:26,613 for Bungoma and 1:20,835 for Kakamega being way below the WHO recommended figure of $1: 1,000[25,26]$.

Information on availability and dispensing practices was collected as part of a larger survey that sought to understand regulatory practices of SDSs in Kenya [20]. All SDSs in the two districts were included in the survey. Data collection was implemented by 5 trained field staff.

The study entailed 3 data collection processes: an SDS census to generate a list of SDSs; a provider survey to describe the availability of medicines (among other outcomes); and a mystery shopper survey to describe the dispensing practices for the medicines. The census was deemed necessary because information held by the health authorities on the numbers and location of SDSs is often incomplete and outdated.

The provider survey sought to describe the availability of a selected range of medicines. The use of tracer conditions and medicines is an accepted method in pharmaceutical sector assessments and medicine use studies [28]. Ten common antibiotics, and 5 antimalarials, were selected from the Kenyan Essential Medicines list and included in the tracer list (Table 1). Questions were asked to persons most involved with the day to day operations of the SDSs.

The mystery shopper survey is a covert technique utilized in studying practices and behavior, where providers - SDS attendants in this case - are blinded to the clients' research agenda [29]. The mystery shopper method was preferred for its ability to minimize bias; it was feared that other methods such as direct observation would lead to behavior modification (the Hawthorne Effect). Two mystery shopper scenarios were designed to describe the prevalence of 3 unlawful practices; selling partial doses of medicines, selling prescription-onlymedicines without a prescription, and stocking medicines that had been pilfered from public facilities. In the first scenario, mystery shoppers requested sub-therapeutic doses of the antibiotic amoxicillin to manage an adult patient with symptoms of acute respiratory infection (ARI), whereas in the second, the shoppers requested partial doses of either the artemisinin monotherapy (AMT) dihydroartemisinin, or any available artemisinin combination therapy (ACT). The use of AMT was discouraged by WHO following evidence showing it led to increased resistance to artemisinin-based treatments [30]. Public facility ACTs were identified based on evidence of a Government of Kenya logo on the blister packaging. This could not be done for antibiotics, as they come as loose tablets, and do not usually have the government logo.

To avoid arousing suspicion, the mystery shoppers were trained to be only moderately persistent, and to walk away if the attendant refused to sell. Once out of sight, they recorded the key features of the interaction in a standard form. Each SDS was visited twice by 2 different shoppers, each presenting one scenario. Care was taken to ensure staff only presented scenarios in shops they had not visited during the census. As shops in more rural areas tend to have slower client flow, visits were planned to coincide with the relatively busier market days, and the 2 scenarios presented on separate days wherever possible. This was done to ensure attendants did not get suspicious on seeing strangers asking for medicines. Another precaution taken to avoid raising suspicion was ensuring that mystery shoppers carried loose change, and that they dressed down appropriately to fit in with the rural environment. Each mystery shopper was trained to present only one scenario to ensure they did not get confused between the 2 scenarios when talking to SDS operators.

All survey data were collected between September and December 2009.

Data were entered into MS Access 2007 database by 2 independent 


\begin{tabular}{|c|c|c|c|c|c|c|c|}
\hline \multirow[b]{2}{*}{ Characteristics } & \multirow{2}{*}{$\begin{array}{c}\text { Overall } \\
\text { Total }\end{array}$} & \multicolumn{3}{|c|}{ Districts } & \multicolumn{3}{|c|}{ Locations } \\
\hline & & Bungoma n (\%) & Kakamega n (\%) & p-value & Urban n (\%) & Rural n (\%) & p-value \\
\hline Number of shops & 213 & 120 & 93 & - & 65 & 148 & - \\
\hline \multicolumn{8}{|l|}{ Antimicrobials } \\
\hline Amoxicillin & $200(94)$ & $111(93)$ & $89(96)$ & 0.300 & $60(92)$ & $140(95)$ & 0.500 \\
\hline Cotrimoxazole & $203(95)$ & $113(94)$ & $90(97)$ & 0.400 & $61(94)$ & $142(96)$ & 0.500 \\
\hline Erythromycin & $134(63)$ & $74(62)$ & $60(65)$ & 0.700 & $52(80)$ & $82(55)$ & 0.001 \\
\hline Tetracycline & $144(68)$ & $78(65)$ & $66(71)$ & 0.400 & $48(74)$ & $96(65)$ & 0.200 \\
\hline Doxycycline & $137(64)$ & $70(58)$ & $67(72)$ & 0.040 & $50(77)$ & $87(59)$ & 0.010 \\
\hline Ciprofloxacin & $123(58)$ & $71(59)$ & $52(56)$ & 0.600 & $43(66)$ & $80(54)$ & 0.100 \\
\hline Chloramphenicol & $76(36)$ & $40(33)$ & $36(39)$ & 0.400 & $35(54)$ & $41(28)$ & $<0.001$ \\
\hline Isoniazid & $3(1)$ & $3(3)$ & $0(0)$ & 0.100 & $3(5)$ & 0 & 0.008 \\
\hline Rifampicin & $15(7)$ & $9(8)$ & $6(6)$ & 0.700 & $11(17)$ & $4(3)$ & $<0.001$ \\
\hline Penicillin & $124(58)$ & $66(55)$ & $58(62)$ & 0.300 & $40(62)$ & $84(57)$ & 0.500 \\
\hline \multicolumn{8}{|l|}{ Antimalarials } \\
\hline ACTs & $93(44)$ & $46(38)$ & $47(51)$ & 0.070 & $44(68)$ & $49(33)$ & $<0.001$ \\
\hline Dihydroartemisinin & $10(5)$ & $2(2)$ & $8(9)$ & 0.020 & $6(9)$ & $4(3)$ & 0.030 \\
\hline Amodiaquine & $41(19)$ & $33(28)$ & $8(9)$ & 0.001 & $13(20)$ & $28(19)$ & 0.800 \\
\hline SP & $145(68)$ & $68(57)$ & $77(83)$ & $<0.001$ & $44(68)$ & $101(68)$ & 0.900 \\
\hline Quinine & $150(70)$ & $77(64)$ & $73(78)$ & 0.020 & $49(75)$ & $101(68)$ & 0.300 \\
\hline
\end{tabular}

Table 1: Availability of selected medicines in SDS in urban and rural locations of the 2 districts $(n=213)$.

clerks, and inconsistencies addressed by checking against the filled questionnaires. Datasets were subsequently transferred into Stata v11.0 for analysis (Stata Corporation, TX, USA).

The primary unit of analysis was the SDS for all variables. The analysis was conducted at 2 levels; first to describe availability of the tracer medicines, and secondly, to explore patterns of association. For the first part, cross-tabulations were done to check the availability of medicines across the 2 districts and locations, using chi-square tests. The second part of analysis explored associations between selected shop and staff characteristics, and dispensing practices. Firstly, univariate logistic regression analysis was conducted to check for the strength of association between the variables, and corresponding Wald test $p$-values reported. This was followed by a systematic selection of variables for inclusion into a multivariate model for adjusted analysis.

The district and location variables were under a priori assumption that they are associated with dispensing practices. While the districts were selected from the same region, we expected that having different health management teams would influence behavior among SDSs. We also felt the rural and urban SDSs would behave differently. Shops were classified as urban if located in the main town in the district, or within 3 kilometers of the town. All shops situated in smaller market centers and villages further than 3 kilometers of town were classified as rural. The cut-off was an estimate informed by observed changes in infrastructure and business activities as one moved away from the main town in both districts. Distances were estimated using survey vehicle odometers.

Because the district and location variables were unlikely to explain all variation, a stepwise selection algorithm was applied to identify other explanatory variables. Variables were loosely grouped into 3 sets: shop factors, staff factors, and regulatory factors. Only variables with a univariate $p$-value of $<0.2$ were selected for the multivariate model. The $\mathrm{p}<0.2$ cut-off point was informed by arguments that lower cut-offs may fail to identify important variables, whereas higher cut-offs make the model less robust [31,32]. In the final model, variables included were district, shop location, display of licenses, pharmacy qualification, knowledge of the name of the law governing pharmacy practice, and whether the shop had received a regulatory visit over the last year.

Institutional ethical approval was provided by both the KEMRI/
Welcome Trust Research Programme and the London School of Hygiene and Tropical Medicine, and national approval given by the KEMRI/National Ethical Review Committee.

\section{Findings}

We identified 224 operational SDSs in the 2 districts. These numbers were much higher than the estimates based on projections from previous work around the Bungoma area, and on numbers provided at the respective district health offices (where staff had estimated a combined total for both districts of roughly 110 SDSs).

The results presented in this section are stratified, first by district (Bungoma and Kakamega), then location (rural and urban). Thirty shops were situated in urban locations in Bungoma, with the Kakamega urban location having a total of 35 shops. Whereas the 2 mystery shopper scenarios were conducted across all shops (130 in Bungoma and 94 in Kakamega), provider surveys were completed in 120 and 93 shops in Bungoma and Kakamega respectively, giving a total of 213 shops. Refusal to participate was the reason behind the lower response rates for the latter survey, with more staff refusing to consent in Bungoma (10 refusals compared to only one in Kakamega). The main reason given for refusals was the absence of staff-in-charge or the shop owner. Only shops where both surveys were completed were included in the analysis ( $n=213$, equivalent to a $95 \%$ response rate) to allow direct assessment of the patterns of association between SDS characteristics recorded in the provider survey, and practice-related findings obtained using mystery shoppers.

\section{Availability of antimalarials and antibiotics}

Amoxicillin and cotrimoxazole were the most widely available antimicrobials ( $>90 \%$ of SDSs), with sulphur-based antimalarials (sulfadoxine and pyremthamine combination (SP)) and quinine the most widely available antimalarials ( $70 \%$ and $68 \%$ respectively). Tuberculosis medicines and chloramphenicol were the least available antimicrobials, with the recently withdrawn AMT being the least available antimalarial.

With the exception of doxycycline, variation in availability of antimicrobials across districts was minimal. However, there were 
notable inter-district variations in availability of antimalarials, with SPs being more widely available in Kakamega shops, and amodiaquine having a higher availability in Bungoma $(\mathrm{p}<0.001)$. The availability of ACTs was relatively low overall (44\%).

Stratification by location resulted in clearer variations, with the availability of 3 antimicrobials - erythromycin, chloramphenicol and rifampicin - being significantly more available in urban than rural shops $(\mathrm{p}<0.001)$. However, nearly all SDSs across both locations had amoxicillin and cotrimoxazole in stock. Variations in antimalarial availability were less pronounced; only ACTs showed substantial variation, with urban shops having a higher availability overall $(\mathrm{p}<0.001)$

\section{Dispensing practices}

Nearly all shops stocking amoxicillin sold the medicine to mystery shoppers, with only one quarter asking about additional symptoms, and/or advising against buying a partial dose (Table 2). Analysis by location showed rural shops to have a higher likelihood of dispensing amoxicillin without prescription (97\% compared to $79 \%, \mathrm{p}<0.001$ ). Urban shops, on the other hand, were more likely to ask about additional symptoms, and advise clients against buying an incomplete dose of the medicine ( $\mathrm{p}<0.001$ in both cases).

None of the shops sold an artemisinin monotherapy to mystery shoppers, with all reporting that they did not stock the medicine anymore. As for ACTs, dispensing patterns were largely similar to those observed with amoxicillin, although attendants were more likely to ask ARI clients for additional symptoms compared to malaria clients. While dispensing practices were poor for both medicines, more SDSs dispensed amoxicillin inappropriately compared to ACTs ( $90 \%$ compared to $80 \%$ ). However, those buying the partial doses of amoxicillin were more likely to be advised against the habit $(27 \%$ compared to $18 \%$ for ACTs).

Labeling of medicine was poor overall, with most attendants failing to write proper instructions on how the medicine should be administered. The most common instruction format was ' $2 \times 3$ ', which is an abbreviation for 'take 2 capsules every 8 hours'.

The ACTs purchased were classified as either public or private sector origin based on examination of packaging. Out of 85 shops that sold an ACT to mystery shoppers, $48 \%$ sold ACTs with a Government of Kenya logo on the packaging, indicating that they had been illegally obtained. The majority of these public sector ACTs had the government labels concealed, either through rubbing out, or by painting over the initials. Two examples are shown in figure 1.

\section{Predictors of dispensing practices of specialized drug shops}

We explored the patterns of association between dispensing practices and 6 predictors: district, location, pharmacy qualification, display of licenses, knowing the name of the pharmacy law and whether an inspection had taken place over the past year.

The multivariate analysis found no meaningful association between all selected predictors and dispensing low dose ACTs (Table 3). However, shops in urban locations had significantly lower odds of dispensing partial doses of amoxicillin compared to those operating in rural locations $(0.08,95 \%$ CI $0.01-0.81, p=0.030$ for the adjusted analysis). No other potential predictors were found to be related to dispensing practices for amoxicillin.

Shop location was associated with selling public sector ACTs, with the practice being more common in rural SDSs (adjusted odds ratio of $0.11, \mathrm{p}<0.001)$ (Table 4). Regulatory inspection $(\mathrm{p}=0.6)$ and presence of staff with pharmacy-related qualifications $(\mathrm{p}=0.3)$ were not found to be associated with selling the unlawfully acquired medicine.

\section{Discussion}

Registered and unregistered pharmacies and drug stores are very widely used as a source of treatment in Sub-Saharan Africa, and are often seen as a more affordable and/or convenient alternative to seeking care at health facilities, benefiting from more reliable drug supplies. It is therefore important that the quality of care offered be understood, and influences on dispensing behavior described. We conducted provider and mystery shopper surveys to assess the availability of key antimalarial and antibacterial medicines, and to describe real-life dispensing practices.

The patterns of medicine availability were largely similar across the 2 study districts, but considerably different across rural and

\begin{tabular}{|c|c|c|c|c|c|c|c|}
\hline \multirow[b]{2}{*}{ Parameter } & \multirow{2}{*}{$\begin{array}{c}\text { Overall } \\
\text { Total }\end{array}$} & \multicolumn{3}{|c|}{ Districts } & \multicolumn{3}{|c|}{ Locations } \\
\hline & & Bungoma & Kakamega & p-value & Urban & Rural & p-value \\
\hline & & n (\%) & $\mathrm{n}(\%)$ & & n (\%) & n (\%) & \\
\hline Number of shops & 213 & 120 & 93 & & 65 & 148 & \\
\hline \multicolumn{8}{|l|}{ Communication with clients } \\
\hline \multicolumn{8}{|l|}{ Mystery shopper scenario 1 (ARI) } \\
\hline Asked about additional symptoms & $53(25)$ & $39(33)$ & $14(15)$ & 0.003 & $38(58)$ & $15(10)$ & $<0.001$ \\
\hline Advised against buying incomplete dose & $57(27)$ & $30(25)$ & $27(29)$ & 0.5 & $30(46)$ & $27(18)$ & $<0.001$ \\
\hline \multicolumn{8}{|l|}{ Mystery shopper scenario 2 (Malaria) } \\
\hline Asked about additional symptoms & $6(3)$ & $5(4)$ & $1(1)$ & 0.2 & $4(6)$ & $2(1)$ & 0.4 \\
\hline Advised against buying incomplete dose & $39(18)$ & $16(13)$ & $23(25)$ & 0.002 & $18(28)$ & $21(14)$ & 0.8 \\
\hline \multicolumn{8}{|c|}{ Dispensing of medicines (of those shops stocking respective medicines during the survey) } \\
\hline Number of shops & 174 & 95 & 79 & & 56 & 118 & \\
\hline Sold sub-therapeutic dose of amoxicillin & $159(91)$ & $86(91)$ & $73(92)$ & 0.7 & $44(79)$ & $115(97)$ & $<0.001$ \\
\hline Number of shops & 106 & 60 & 46 & & 54 & 52 & \\
\hline Sold sub-therapeutic dose of ACT medicine & $85(80)$ & $50(83)$ & $35(76)$ & 0.4 & $40(74)$ & $45(87)$ & 0.1 \\
\hline \multicolumn{8}{|c|}{ Labeling of dispensed medicines (of those shops that dispensed the medicine to mystery shoppers) } \\
\hline Number of shops & 161 & 88 & 73 & & 51 & 110 & \\
\hline Labeled amoxicillin as required by law & $11(7)$ & $6(7)$ & $5(7)$ & 0.9 & $2(4)$ & $9(8)$ & 0.3 \\
\hline Number of shops & 85 & 50 & 35 & & 39 & 46 & \\
\hline Labeled ACT medicine as required by law & $11(13)$ & $5(10)$ & $6(17)$ & 0.3 & $8(21)$ & $3(7)$ & 0.07 \\
\hline
\end{tabular}

Table 2: Dispensing practices for amoxicillin and ACT requested by mystery shoppers. 


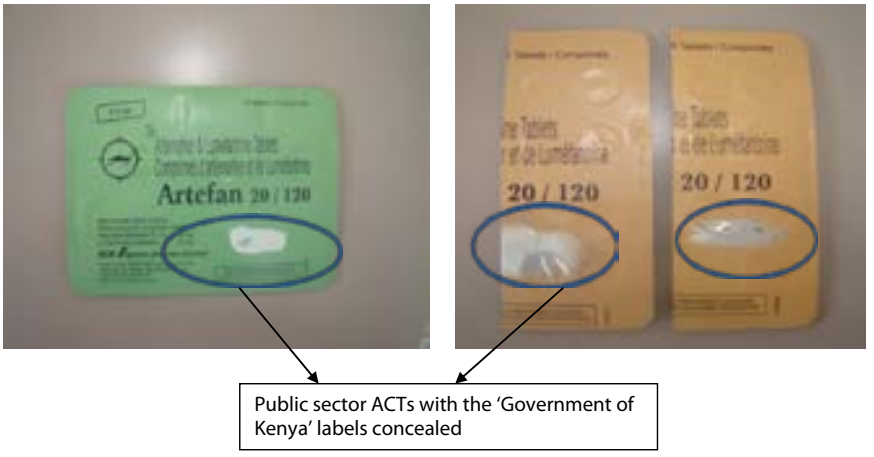

Figure 1: Public sector ACTs found being sold in specialized drug shops.

urban locations. Amoxicillin and cotrimoxazole were the most widely available antibiotics. Wide availability of the 2 antibiotics has also been documented in other countries in SSA, including Zimbabwe and Tanzania [8,33]. As for malaria, SP and quinine were the most widely available, despite the fact that neither is the first-line treatment for uncomplicated malaria. Similar patterns have also been reported in other countries such as Uganda and Nigeria [34]. The high availability of SP came from the fact that it was the predecessor to the current firstline treatment for uncomplicated malaria, and was still significantly cheaper. At the time of the survey, SP was retailing at less than one USD per dose, while proprietary ACTs were selling at anything between USD 8-10 per adult dose.

Tuberculosis medicines on the other hand, were rarely stocked in shops, possibly reflecting successful efforts by the government to control Multi-Drug Resistant Tuberculosis (MDR-TB) through limiting retail sector provision (Personal Communication, Head of the Division of Tuberculosis). This limited retail sector availability was reported despite the fact that the Kenyan government had never officially banned (through Gazette or legislation) private pharmacies from selling TB medicines at the time of the survey. Similarly, artemisinin monotherapies were rarely encountered across both districts, portraying a similar level of success in controlling retail sector provision. Availability of these monotherapies has in the past resulted in inappropriate prescribing behaviour in Kenya, and remains a major problem in other countries like Nigeria and the Democratic Republic of Congo [34]. Understanding reasons underlying the successful minimization of retail provision of the 2 types of medicines may provide useful lessons for policy, and help inform future endeavors aimed at controlling the availability of non-recommended commodities within the market.

Unlike antibiotics, availability of antimalarials varied substantially across the districts. At the time of the survey, official policy stated that amodiaquine should not be sold in pharmacies, and that SPs should only be sold for intermittent preventive treatment (IPT) of malaria in pregnancy [21]. This meant that whereas stocking SPs could be justified; there was no reason to stock amodiaquine, whose availability was particularly high in Bungoma.

As far as dispensing goes, urban shops were more likely to advise clients against buying partial doses of amoxicillin, and less likely to dispense the medicine, although the practice was highly prevalent overall. Additionally, most operators sold amoxicillin and ACTs without prescription, although they exercised more caution when dealing with the latter, with more operators refusing to dispense the medicine altogether. Clients rarely present to pharmacies with prescriptions in Sub-Saharan Africa for various reasons, ranging from poor access to health facilities to general preference for the convenient care provided by retailers [24,35-37]. The reason behind the differences between the 2 medicines is unclear. It may be that staff were better informed on the dangers of selling partial doses of ACTs than amoxicillin, less aware of the correct does for amoxicillin, or because ACTs were provided in agespecific packs, while amoxicillin was more usually sold as loose tablets. Problems of inappropriate dispensing of antibiotics and antimalarials have been widely documented in Kenya [17,38], Tanzania [39], Zaire [40] and Ethiopia [41] among other countries.

Poor labeling of medicines was relatively common across both locations. Nearly all staff wrote dosing instructions using a common abbreviation of the format 'A $\mathrm{x}$ B' (where 'A' and 'B' stand for number of tablets and dosing frequency respectively). Labeling by dispensers was also noted to be a problem in Tanzania, particularly where information on dose duration was concerned [42]. Proper labeling is important at the dispensing level, regardless of whether or not the medicines have a manufacturer's label. Evidence has in the past shown that some manufacturers do not affix appropriate labels on medicines a situation that could result in users confusing treatments $[43,44]$ thus increasing the risk of adverse drug reactions.

We also aimed to describe the patterns of association between regulatory practices of SDSs and selected predictors. The district was found to have little association with most outcomes. Location, on the other hand, was an important predictor across the majority of outcomes. Overall, urban shops offered better care than rural shops, with the latter having a higher likelihood of selling partial doses of medicines and dispensing public sector ACTs. This is not a new observation; past studies have shown urban shops to offer better quality of care. Goel et al., for instance, found urban Kenyan pharmacies to have a higher likelihood of providing correct treatments for diarrhea when compared to those in rural towns, whereas in Zimbabwe, Nyazema et al., found staff in Harare pharmacies to have better knowledge on managing sexually transmitted infections (STIs) compared to those from smaller towns $[33,38]$. Again, the fact that the majority of qualified staff in this study were found in urban shops may have been a key contributor. However, other factors may be equally relevant, including the knowledge and expectations of the clientele, as well as broad contextual factors such as the nature of the competition within the market and the purchasing power of clients. As far as dispensing partial doses of medicine without prescription is concerned, several factors may explain why this happened a lot more across rural locations. These include lower business activity forcing sellers to maximize revenue from the few client visits, lower awareness of the dangers of indiscriminate dispensing, and client demand (whether clients come with a prescription). The importance of the last point is exemplified in Somaliland, where less than $50 \%$ of rural pharmacies reported receiving prescriptions, compared to $90 \%$ of urban pharmacies [24]. However, while urban SDSs performed better than rural shops, it should be noted that the quality of dispensing was poor overall.

As far as training is concerned, having staff with a pharmacy qualification was not protective against dispensing partial doses of medicines, or selling public sector ACTs. While one might expect shops with qualified staff to adhere better to dispensing requirements, such expectations ignore the challenges that come with engaging in businesses where a good proportion of competitors are unqualified. However, it should be noted that some of the shops that reported having qualified staff may not have had the staff present during the mystery shopper visits; indeed, there is evidence showing that SDSs commonly employ qualified staff for registration purposes, only to revert to unqualified staff for daily operations, presumably to avoid 
Citation: Wafula F (2013) Availability and Dispensing Practices for Antimalarials and Antimicrobials in Western Kenyan Pharmacies. Pharmaceut Reg Affairs 2: 106. doi:10.4172/2167-7689.1000106

Page 6 of 8

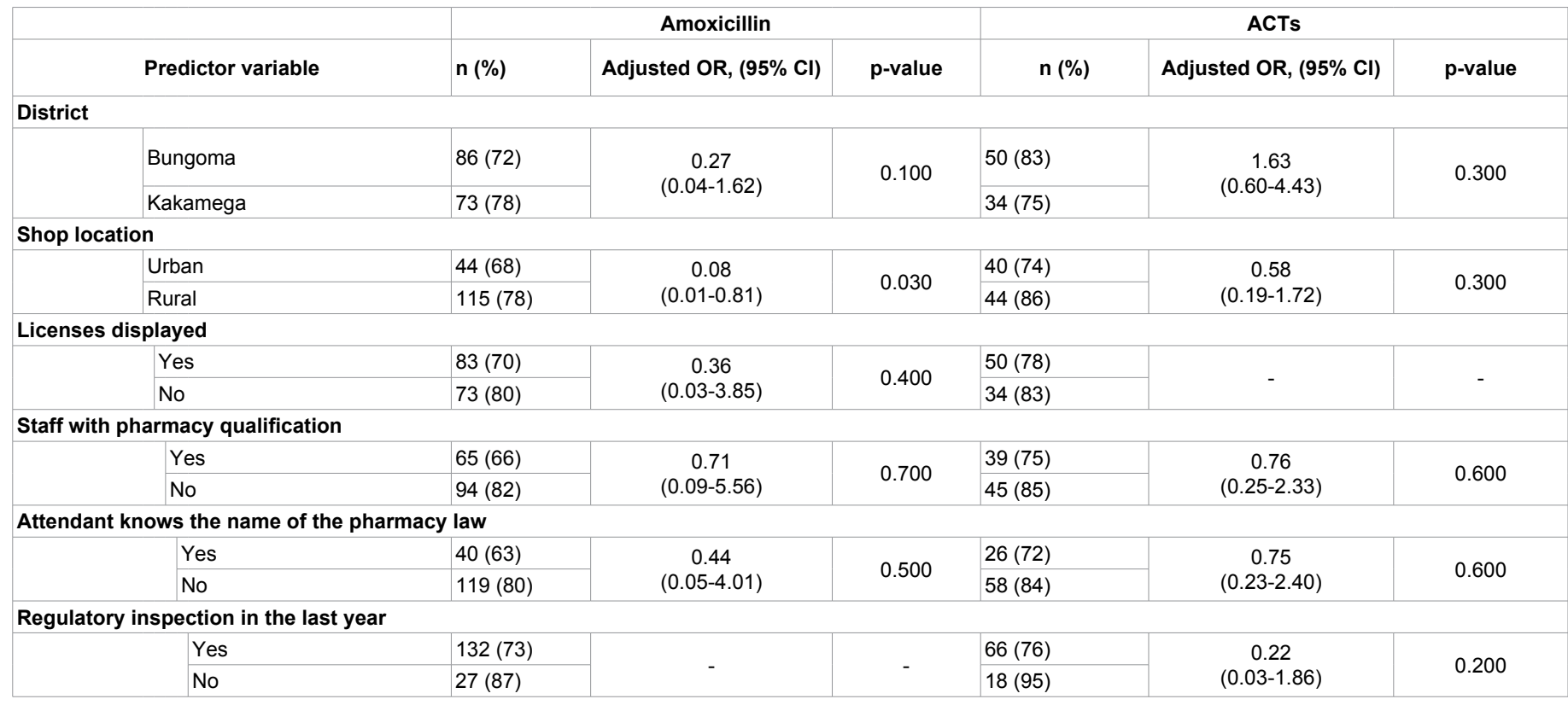

Table 3: Multivariate analysis of predictors for dispensing low dose amoxicillin and ACTs without prescription $(n=213)$.

\begin{tabular}{|c|c|c|c|}
\hline Predictor variable & n (\%) & Adjusted OR, $(95 \% \mathrm{Cl})$ & p-value \\
\hline \multicolumn{4}{|l|}{ District } \\
\hline Bungoma & $31(57)$ & \multirow{2}{*}{$2.29(0.83-6.27)$} & \multirow{2}{*}{0.1} \\
\hline Kakamega & $12(33)$ & & \\
\hline \multicolumn{4}{|l|}{ Shop location } \\
\hline Urban & $9(23)$ & \multirow{2}{*}{$0.11(0.04-0.36)$} & \multirow{2}{*}{$<0.001$} \\
\hline Rural & $34(68)$ & & \\
\hline \multicolumn{4}{|l|}{ Licenses displayed in the premises } \\
\hline Yes & $22(43)$ & \multirow{2}{*}{-} & \multirow{2}{*}{ - } \\
\hline No & $19(54)$ & & \\
\hline \multicolumn{4}{|l|}{ Staff with pharmacy qualification } \\
\hline Yes & $17(40)$ & \multirow{2}{*}{$0.60(0.20-1.81)$} & \multirow{2}{*}{0.300} \\
\hline No & $24(55)$ & & \\
\hline \multicolumn{4}{|l|}{ Knows the name of the pharmacy law } \\
\hline $\begin{array}{l}\text { Yes } \\
\text { No }\end{array}$ & $\begin{array}{l}9(33) \\
32(54)\end{array}$ & $0.73(0.20-2.73)$ & 0.600 \\
\hline \multicolumn{4}{|l|}{ Regulatory inspection in the last year } \\
\hline Yes & $32(46)$ & \multirow[t]{2}{*}{-} & \multirow[t]{2}{*}{-} \\
\hline No & $9(53)$ & & \\
\hline
\end{tabular}

Table 4: Multivariate analysis of predictors for dispensing public sector ACTs $(n=85)$.

paying high salary costs $[7,40,45,46]$. Similarly, knowledge of the name of the law governing pharmacy practice (which could be considered a crude proxy for knowledge about regulation) was not associated with better dispensing, leading one to the conclusion that there are other factors that influence dispensing practices. Previous studies have identified profit incentives, shop location, client characteristics and client demand among others as being equally important $[10,39,47,48]$.

One surprising observation was the fact that shops that had received a regulatory visit were no different from those that had not been inspected over the past year in terms of dispensing practices. While expecting inspections to influence behaviour on its own is presumptive, one would nonetheless anticipate seeing, at the very least, some differences between inspected shops and those that had not received an inspection recently. This pattern points at inadequacies in regulatory enforcement, suggesting that those responsible for inspections were not promoting good dispensing behavior among SDSs.
A potential limitation was the completeness of the SDS census. While care was taken to ensure all shops were captured, the possibility of omitting a shop or two cannot be discounted. There was also the issue of refusals. While these were few overall (5\%), one might expect most refusals to come from shops lacking qualified staff. There was also risk of reporting bias, especially on items that could not be verified easily, for instance, staff qualification.

A more general limitation is the omission of general shops, which are known to stock some fever and malaria medicines in Kenya [49]. The main purpose of the study was to assess how SDSs comply with regulations; for this reason, general shops were omitted, as they are not regulated by provisions governing the health sector.

Findings from the study highlight the risks of inappropriate medicine use. Dispensing antibiotics and antimalarials without prescription can accelerate development of resistance, especially where the medicines are used without a proper indication [50]. Indiscriminate 
dispensing habituates poor medicine use, leading to inappropriate practices such as using antibiotics for upper respiratory tract infections. The risk of resistance is further increased when clients buy incomplete doses of medicines [51]. Although the study was carried out in one part of the country, the effects of resistance are likely to spread to other parts. Indeed, resistance to anti-infective agents is something that is known to have originated from one region.

Policy should focus on strengthening regulatory enforcement, in combination with education for dispensers, and should consider the routine use of mystery shoppers by regulatory bodies to record dispensing practices. However, such regulation and education strategies can be resource intensive. A complementary and potentially cost-effective strategy would be promotion of public awareness about appropriate medicine use.

Other elements of quality of SDS care beyond the scope of this study but equally important include diagnostic capacity and pharmacovigilance. Improving the availability of diagnostic equipment such as malaria rapid diagnostic tests in SDS may reduce inappropriate use of medicines within communities [52], although comparable tests for common bacterial infections are not available. A good pharmacovigilance system should have the ability to trace the origin of medicines found within the community, and allow information on medicine use to be shared. However, pharmacovigilance has been poorly implemented in Kenya and other developing countries, partly due to resource constraints, and partly because of inadequate goodwill and support from stakeholders in the health sector [53].

\section{Conclusion}

This study aimed to describe availability and dispensing practices for antimalarials and antibiotics among Kenyan SDSs. Although the majority of shops had the medicines in stock, there were some ruralurban differences, with rural shops having lower availability overall. However, availability was generally high for more commonly used medicines, particularly amoxicillin and cotrimoxazole.

As far as dispensing practices are concerned, poor practices were reported, particularly in rural areas. Here, the practice of dispensing medicines without prescription was widely reported. To make matters worse, most operators sold partial doses of the medicines, even where they had advised the clients against incomplete dosing. Key shop characteristics such as the presence of qualified staff, and frequency of regulatory inspections were found to have little association with dispensing practices. This suggested that there are factors beyond qualification and inspections that influence dispensing practices for antimalarials and antibiotics.

The study highlighted the risks of inappropriate medicine use within communities. Indiscriminate dispensing habituates poor medicine use practices, which can result in the development and spread of resistance. Policy should focus on strengthening regulatory enforcement, in combination with education for dispensers, and promotion of public awareness. More research is required to describe in-depth, reasons underlying the dispensing practices observed, and how they can be improved to strengthen the role of retailers in provision of antimalarials and antibiotics within rural communities.

\section{Acknowledgment}

We would like to acknowledge statistical advice from Drs. Phillip Ayieko and Tansy Edwards. The research was funded through a fellowship grant from the Wellcome Trust to the first author (grant number \#083078/Z/07/Z). FW and CG are affiliated with the KEMRI/Wellcome Trust Research Programme, which is funded by the Wellcome Trust (grant \# 077092). This paper was published with the permission of the director of KEMRI.

\section{References}

1. Jamison T, Feachem R, Makgoba M, Bos E, Baingana F, et al. (2006) Disease and Mortality in Sub-Saharan Africa. (2ndedn), Washington, DC: The World Bank.

2. United Nations. Changing Levels and Trends in Mortality: the role of patterns of death by causes Department of Economic and Social Affairs, Population Division. United Nations publication, ST/ESA/SER.A/318; 2012.

3. Jones G, Steketee RW, Black RE, Bhutta ZA, Morris SS (2003) How many child deaths can we prevent this year? Lancet 362: 65-71.

4. McGready R, Boel M, Rijken MJ, Ashley EA, Cho T, et al. (2012) Effect of early detection and treatment on malaria related maternal mortality on the northwestern border of Thailand 1986-2010. PLoS One 7: e40244

5. Noor AM, Zurovac D, Hay SI, Ochola SA, Snow RW (2003) Defining equity in physical access to clinical services using geographical information systems as part of malaria planning and monitoring in Kenya. Trop Med Int Health 8 : 917-926.

6. Sudoi RK, Githinji S, Nyandigisi A, Muturi A, Snow RW, et al. (2012) The magnitude and trend of artemether-lumefantrine stock-outs at public health facilities in Kenya. Malar J 11: 37

7. Goodman C, Kachur SP, Abdulla S, Bloland P, Mills A (2007) Drug shop regulation and malaria treatment in Tanzania--why do shops break the rules, and does it matter? Health Policy Plan 22: 393-403.

8. Health Research for Action. Review of the Accredited Drug Dispensing Outlets (ADDO) Roll out Programme in Tanzania. Belgium: Report by Health Research for Action (HERA), Belgium; 2006.

9. Wafula FN, Miriti EM, Goodman CA (2012) Examining characteristics, knowledge and regulatory practices of specialized drug shops in Sub-Saharan Africa: a systematic review of the literature. BMC Health Serv Res 12: 223.

10. Wafula FN, Goodman CA (2010) Are interventions for improving the quality of services provided by specialized drug shops effective in sub-Saharan Africa? A systematic review of the literature. Int J Qual Health Care 22: 316-323.

11. Goodman C, Brieger W, Unwin A, Mills A, Meek S, et al. (2007) Medicine sellers and malaria treatment in sub-Saharan Africa: what do they do and how can their practice be improved? Am J Trop Med Hyg 77: 203-218.

12. Buabeng KO, Duwiejua M, Dodoo AN, Matowe LK, Enlund H (2007) Selfreported use of anti-malarial drugs and health facility management of malaria in Ghana. Malar J 6: 85.

13. Igun UA (1994) Reported and actual prescription of oral rehydration therapy for childhood diarrhoeas by retail pharmacists in Nigeria. Soc Sci Med 39: $797-$ 806

14. WHO (2002) Promoting rational use of medicines: core components. WHO policy perspectives on medicines. Geneva, Switzerland.

15. Amin AA, Marsh V, Noor AM, Ochola SA, Snow RW (2003) The use of formal and informal curative services in the management of paediatric fevers in four districts in Kenya. Trop Med Int Health 8: 1143-1152.

16. Chuma J, Gilson L, Molyneux C (2007) Treatment-seeking behaviour, cost burdens and coping strategies among rural and urban households in Coastal Kenya: an equity analysis. Trop Med Int Health 12: 673-686.

17. Kwena Z, Sharma A, Wamae N, Muga C, Bukusi E (2008) Provide characteristics among staff providing care to sexually transmitted infection selfmedicating patients in retail pharmacies in Kibera slum, Nairobi, Kenya. Sex Transm Dis 35: 480-483.

18. Molyneux CS, Mung'Ala-Odera V, Harpham T, Snow RW (1999) Materna responses to childhood fevers: a comparison of rural and urban residents in coastal Kenya. Trop Med Int Health 4: 836-845.

19. Barnes J, O'Hanlon B, Feeley F, McKeon K, Gitonga N, et al. (2009) Kenya Private Health Sector Assessment. Private Sector Partnerships-One project Abt Associates Inc: Bethesda, MD.

20. Wafula $F$ (2012) Understanding the operation and regulation of specialized drug shops in Kenya: PhD Thesis. Open University (Milton Keynes) \& Department of Public Health and Policy, London School of Hygiene and Tropical Medicine (London).

21. Division of Malaria Control (2010) National Guidelines for the Diagnosis, Treatment and Prevention of Malaria in Kenya: Ministry of Public Health and Sanitation, Ministry of Medical Services. 
Citation: Wafula F (2013) Availability and Dispensing Practices for Antimalarials and Antimicrobials in Western Kenyan Pharmacies. Pharmaceut Reg Affairs 2: 106. doi:10.4172/2167-7689.1000106

Page 8 of 8

22. MoPHS, MoMS (2010) National Ministry of Medical Services. Ministry of Public Health and Sanitation, Ministry of Medical Services.

23. Mangham LJ, Cundill B, Ezeoke O, Nwala E, Uzochukwu BS, et al. (2011) Treatment of uncomplicated malaria at public health facilities and medicine retailers in south-eastern Nigeria. Malar J 10: 155.

24. Mazzilli C, Ahmed R, Davis A (2009) The Private Sector and Health: A survey of Somaliland private pharmacies: UNICEF Somalia. The European Union, Somaliland Pharmaceutical Association

25. Ministry of Planning (2008) Bungoma South District Development Plan 20082012: Ministry of State for Planning, National Development and Vision 2030.

26. Ministry of Planning (2008) Kakamega Central District Development Plan 2008 2012: Ministry of State for Planning, National Development and Vision 2030.

27. http://opendata.go.ke/Poverty/District-Poverty-Data-KIHBS-2005-6/pnvr-waq2

28. WHO (2007) WHO Operational package for assessing and evaluating country pharmaceutical Situations: Guide for coordinators and data collectors. Geneva, Switzerland: WHO Technical Cooperation for Essential Drugs and Traditional Medicine.

29. Madden JM, Quick JD, Ross-Degnan D, Kafle KK (1997) Undercove careseekers: simulated clients in the study of health provider behavior in developing countries. Soc Sci Med 45: 1465-1482.

30. WHO (2006) WHO Guidelines for the treatment of malaria: World Health Organization.

31. Bursac Z, Gauss CH, Williams DK, Hosmer DW (2008) Purposeful selection of variables in logistic regression. Source Code Biol Med 3: 17.

32. Hosmer DW, Lemeshow S (2000) Applied Logistic Regression. NewYork Wiley.

33. Nyazema N, Viberg N, Khoza S, Vyas S, Kumaranayake L, et al. (2007) Low sale of antibiotics without prescription: a cross-sectional study in Zimbabwean private pharmacies. J Antimicrob Chemother 59: 718-726.

34. O'Connell KA, Gatakaa H, Poyer S, Njogu J, Evance I, et al. (2011) Got ACTs? Availability, price, market share and provider knowledge of anti-malarial medicines in public and private sector outlets in six malaria-endemic countries. Malar J 10: 326.

35. Afolabi AO (2008) Factors influencing the pattern of self-medication in an adult Nigerian population. Ann Afr Med 7: 120-127.

36. Awad A, Eltayeb I, Matowe L, Thalib L (2005) Self-medication with antibiotics and antimalarials in the community of Khartoum State, Sudan. J Pharm Pharm Sci 8: 326-331.

37. Crabbé F, Carsauw H, Buvé A, Laga M, Tchupo JP, et al. (1996) Why do men with urethritis in Cameroon prefer to seek care in the informal health sector? Genitourin Med 72: 220-222.

38. Goel PK, Ross-Degnan D, McLaughlin TJ, Soumerai SB (1996) Influence of location and staff knowledge on quality of retail pharmacy prescribing for childhood diarrhea in Kenya. Int J Qual Health Care 8: 519-526.

39. Hetzel MW, Dillip A, Lengeler C, Obrist B, Msechu JJ, et al. (2008) Malaria treatment in the retail sector: knowledge and practices of drug sellers in rura Tanzania. BMC Public Health 8: 157.

40. Ntambwe M, Luwombo I, Djurna O (1994) Who sells drugs in rural Zaire? World Health Forum 15: 62-63.

41. Abula T, Worku A, Thomas K (2006) Assessment of the dispensing practices of drug retail outlets in selected towns, north west Ethiopia. Ethiop Med $\mathrm{J} 44$ 145-150.

42. RPM Plus (2007) Improving Child Health through the Accredited Drug Dispensing Outlet Program: Baseline Survey from Five Districts in Tanzania, September 2006

43. Battersby A, Goodman C, Abondo CRM (2003) Improving the supply, distribution and use of antimalarial drugs by the private sector in Tanzania.

44. Kachur SP, Black C, Abdulla S, Goodman C (2006) Putting the genie back in the bottle? Availability and presentation of oral artemisinin compounds at retail pharmacies in urban Dar-es-Salaam. Malar J 5: 25.

45. Maïga MD, Diawara A (2006) [Study on the availability and cost of medicines in the private sector in Mali]. Med Trop (Mars) 66: 565-568.

46. Mayhew S, Nzambi K, Pépin J, Adjei S (2001) Pharmacists' role in managing sexually transmitted infections: policy issues and options for Ghana. Health Policy Plan 16: 152-160.

47. Patrick Kachur S, Schulden J, Goodman CA, Kassala H, Elling BF, et al. (2006) Prevalence of malaria parasitemia among clients seeking treatment for fever or malaria at drug stores in rural Tanzania 2004. Trop Med Int Health 11: 441-451.

48. Okeke TA, Uzochukwu BS, Okafor HU (2006) An in-depth study of patent medicine sellers' perspectives on malaria in a rural Nigerian community. Malar J 5: 97.

49. AMFm Independent Evaluation Team. Independent Evaluation of Phase 1 of the Affordable Medicines Facility - malaria (AMFm), Multi-Country Independent Evaluation Report: Final Report (2012) ICF International and London School of Hygiene and Tropical Medicine, Calverton, Maryland and London.

50. Okeke IN, Laxminarayan R, Bhutta ZA, Duse AG, Jenkins P, et al. (2005) Antimicrobial resistance in developing countries. Part I: recent trends and current status. Lancet Infect Dis 5: 481-493.

51. Byarugaba DK (2004) A view on antimicrobial resistance in developing countries and responsible risk factors. Int J Antimicrob Agents 24: 105-110.

52. Cohen JM, Woolsey AM, Sabot OJ, Gething PW, Tatem AJ, et al. (2012) Public health. Optimizing investments in malaria treatment and diagnosis. Science 338: 612-614.

53. WHO (2002) The Importance of Pharmacovigilance- Safety monitoring of medicinal products. Geneva, Switzerland. 